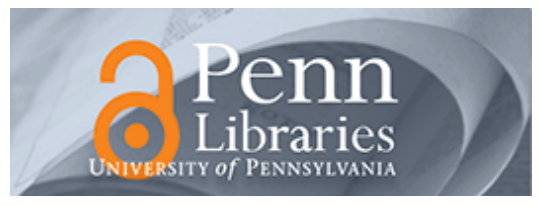

University of Pennsylvania ScholarlyCommons

April 2003

\title{
Has the Concentration of Income and Poverty among Subsurbs of Large US Metropolitan Areas Changed over Time?
}

Janice F. Madden

University of Pennsylvania, madden@ssc.upenn.edu

Follow this and additional works at: https://repository.upenn.edu/penniur_papers

Madden, Janice F., "Has the Concentration of Income and Poverty among Subsurbs of Large US Metropolitan Areas Changed over Time?" (2003). Penn IUR Publications. 12.

https://repository.upenn.edu/penniur_papers/12

Copyright Regional Science Association International. Reprinted from Papers in Regional Science, Volume 82, Issue 2, April 2003, pages 249-275.

This paper is posted at ScholarlyCommons. https://repository.upenn.edu/penniur_papers/12

For more information, please contact repository@pobox.upenn.edu. 


\title{
Has the Concentration of Income and Poverty among Subsurbs of Large US Metropolitan Areas Changed over Time?
}

\author{
Abstract \\ American policy analysts have assumed that poverty is increasingly concentrating in the inner suburbs of \\ large cities. This study demonstrates that that assumption is inaccurate. Using data on household \\ income and poverty for suburban civil divisions from the 1970, 1980, and 1990 US Censuses, this article \\ calculates values for two indicators of the change in the relative concentration of income and poverty, the \\ coefficient of variation, and a regression of changes on initial values. Results indicate that poverty and \\ income concentrations have not generally increased among suburbs over the last twenty years. There is \\ evidence, however, that poverty has increasingly concentrated within some suburban municipalities of \\ older metropolitan areas in the northeast and midwest.

\section{Comments} \\ Copyright Regional Science Association International. Reprinted from Papers in Regional Science, Volume \\ 82, Issue 2, April 2003, pages 249-275.
}




\title{
Has the concentration of income and poverty among subsurbs of large US metropolitan areas changed over time? ${ }^{\star}$
}

\author{
Janice Fanning Madden \\ University of Pennsylvania, 3718 Locust Walk, Philadelphia, PA 19104-6299, USA \\ (e-mail: madden@ssc.upenn.edu)
}

Received: 16 June 2001 / Accepted: 12 July 2002

\begin{abstract}
American policy analysts have assumed that poverty is increasingly concentrating in the inner suburbs of large cities. This study demonstrates that that assumption is inaccurate. Using data on household income and poverty for suburban civil divisions from the 1970, 1980 and 1990 US Censuses, this article calculates values for two indicators of the change in the relative concentration of income and poverty, the coefficient of variation, and a regression of changes on initial values. Results indicate that poverty and income concentrations have not generally increased among suburbs over the last twenty years. There is evidence, however, that poverty has increasingly concentrated within some suburban municipalities of older metropolitan areas in the northeast and midwest.
\end{abstract}

JEL classification: R12, R23

Key words: Suburban poverty, metropolitan income distribution, suburban inequality, metropolitan concentration of poverty

\section{Introduction}

Over time, lower income households have become more concentrated in US central cities and higher income households have become more concentrated in their suburbs, at least since 1969. The relatively increasing concentration of poor and other lower income households within the central city and of higher income households among the suburbs is characteristic of large metropolitan areas (MSAs) in the United States. While there is no doubt that, over time, poorer households have become increasingly localized within the central cities of large MSAs in the US,

* This research was partially supported by the Brookings Institution Center on Urban and Metropolitan Policy. Scott Stoner-Eby painstakingly put together the data across censuses for a consistently bounded set of suburban jurisdictions. Comments from anonymous referees improved the manuscript. 
some observers have speculated that there is also a growing concentration of poorer households within some suburban municipalities. For example, Abbot (2002, p. 37) writes "we must face the fact that ... central city renewal is driving poverty into inner-ring suburbs and sometimes even beyond." Orfield (1997, 2002) identifies "older suburbs" as well as "inner ring" suburbs as more recent sites for residential concentrations of the urban poor. Orfield $(2002$, p. 46) reports that, while $28 \%$ of the populations of 25 large MSAs reside in the central cities, an incredible $40 \%$ reside in suburbs that he defines as "at risk."1

A surprisingly small number of studies have actually examined the relative economic conditions of suburbs. As most of these studies do not measure changes over time, they cannot provide evidence on relative changes in the concentration of income or poverty among suburbs. The few studies that do include data from more than one time period usually examine relatively small numbers of suburbs and ignore the biases introduced by changes in the municipality boundaries over time.

Schneider and Logan (1985) look at 577 suburban municipalities (in 29 large MSAs) with a population of at least 10,000 in 1977 and find that 53 were "poor," in that their location quotient for the MSA's poorest families was greater than two. Although they present no data, these authors also claim that these poor suburbs were disproportionately inner suburbs and were similar to their central cities with respect to income of residents. Logan and Golden (1986) examine the 1960 to 1980 changes in a range of social and economic characteristics of 990 incorporated suburbs with populations greater than 10,000 in 1980, from 52 large MSAs. They identify older manufacturing suburbs and older residential suburbs with low levels of both manufacturing and trade employment as those "facing the most difficult social and fiscal situations."

Bollens (1988) defines poor or troubled suburbs as those with median family incomes below that of the average for 34 large central cities. His study of suburban units with populations over 10,000 in one of the 100 largest (population) MSAs identifies approximately one in seven suburbs to be troubled in 1960, 1970 and 1980. Although he observes that the trend over twenty years is steady, he also identifies a group of "extremely troubled suburbs," whose median family income was below $90 \%$ of the central cities means, and finds that particular group to have increased over time from 25 to 34 suburbs. He observes that the troubled suburbs in the northeast and north central regions include suburbs which were "satellites" (formerly independent cities) or were manufacturing-oriented and had developed early in the metropolitan history. In the newer MSAs of the south and west, the troubled suburbs were semi-rural and agricultural.

Bourne (1993), in his study of Canadian suburbs, found that suburbs which had been primarily residential, and had functioned as "bedroom communities," were

\footnotetext{
1 While Orfield does not provide either the algorithm or the data used to identify "at risk" suburbs, he appears to be using data estimates (i.e., 1998 population density and population growth between 1993 and 1998) and administrative data (eligibility for school lunch programs) that are known to be erratic and inaccurate for much larger geographic areas. The use of these data for cross-sectional comparisons of suburban municipalities is highly questionable.
} 
less likely to experience increasing poverty than those with industrial bases similar to the central city.

The possibility that poverty is changing its relative concentration or dispersion across suburban governmental jurisdictions is important for understanding the implications of changes in the suburbs for the US system of financing public goods and services. US suburbs are rather unique in that they are independent municipalities that tax their residents and provide primary and secondary education, fire and police protection, sanitation, and other governmental services. They use their taxation and public goods and service packages to compete with the central city for metropolitan residents. Jurisdictions with a proportionately higher number of poor residents must tax richer residents at significantly higher rates than those jurisdictions with fewer poor. Such jurisdictions must tax richer residents more because, although similar levels of governmental goods and services are ultimately provided to each resident of a jurisdiction or municipality, it is more costly to provide a given level of governmental goods or services to poorer residents than to richer residents. ${ }^{2}$ For this reason, the US local governmental system provides incentives - in addition to those arising from the changing spatial economics of production or changing preferences for housing - for the non-poor to locate outside the central cities, which include relatively more poor. These additional incentives to locate in the suburbs increase as the city's poverty rate grows relative to that of competing suburban jurisdictions. If some suburban jurisdictions are now becoming poorer relative to other suburbs, the US local governmental system may be creating similar incentives for the non-poor to leave those suburbs. Some suburban jurisdictions would then face taxation and expenditure issues similar to those in the central city and also be facing loss of non-poor residents. ${ }^{3}$ In this public policy context, the issue of shifts in the location of the poor among jurisdictions or municipalities is the important suburban geographic metric or unit for examining changes in suburban poverty.

Two essential concerns, among others, are addressed here: Firstly, are there changes in the intrametropolitan locations of income and poverty which affect the ability of some suburban governments and of the central city to compete for metropolitan residents? Secondly, has the concentration of poverty and income among suburban municipalities of large metropolitan areas increased over time? I construct a data set that includes the entire suburban area of each metropolitan area, and accounts for changes in municipality boundaries over 20 years. To compare poverty levels and income among suburbs to that of their central city, I implement two indicators or measures of relative changes in the concentration of poverty or

\footnotetext{
2 Janet Pack (1998) provides a series of estimates of increases in costs of providing local public goods and services to poor populations in central cities with over 300,000 residents. She finds that per capita expenditures on non-poverty related public goods and services are $21 \%$ higher in high poverty central cities than in low poverty ones.

3 Of course a lower income suburb must impose a higher tax rate to provide the same real level of public goods and services as a higher income suburb (in the same way that a lower income household must spend a higher share of its income than a higher income household to purchase a given commodity). While differences in the fiscal capacities of poor and rich suburbs may raise distributional issues, they do not raise efficiency issues. That is, they do not create different prices for the same public good for richer households.
} 
income: the coefficient of variation and the coefficient of the regression of the rate of change of suburbs in an MSA on their initial levels of income and poverty.

\section{Data and approach}

The MSA boundaries and designations of the US Census for the 1990 Census are used in this analysis. The general concept of a metropolitan area is one of a large population nucleus, together with adjacent communities, which have a high degree of economic and social integration with that particular nucleus. The boundaries of metropolitan areas, as designated and periodically updated by the United States Office of Management and Budget, are used by Federal agencies to produce, analyze and publish data on metropolitan areas. ${ }^{4}$

\subsection{Central cities}

The central city is the "population nucleus," the largest city, of the metropolitan area. In some cases more than one city in the metropolitan area is labeled as a central city by the Census in 1990. Because my interest is the relationship between the largest city and outlying jurisdictions, I use only the largest city as the central city in the metropolitan area, with four exceptions in three metropolitan areas. The exceptions are metropolitan areas where the central cities are relatively close in size: Dallas-Fort Worth, Minneapolis-St. Paul and San Francisco-Oakland-San Jose. All other civil divisions in the metropolitan area are considered as suburbs.

\subsection{Suburbs}

Because the study of changes in the intra-metropolitan concentration of poverty requires data that allow comparisons among suburbs within a metropolitan area, it is necessary to distinguish among suburbs, as well as between the central city and the suburbs. The study therefore requires consistent data for individual suburban governments within each metropolitan area.

There are three forms in which income and demographic data on individual suburbs across the nation are reported: the census tract, the minor civil division/census county division and the county. 5

\footnotetext{
4 The metropolitan areas are the 1990 MSAs (metropolitan statistical areas), each named for one or more central city. There are also 17 clusters of MSAs which include 19 of the central cities in this article. Each cluster is called a consolidated metropolitan statistical area (CMSA). In such a cluster, each of the component MSAs is uniquely identified, but each also has social and economic connections to the other MSAs in the cluster required by the US Census in order to be included as a clustered MSA or CMSA. For example, New York City CMSA comprises 12 MSAs, Chicago CMSA comprises 6 MSAs and the Los Angeles CMSA comprises 4 MSAs. This article uses the MSA for each central city as the metropolitan area with four exceptions. For Dallas-Fort Worth and San Francisco-Oakland-San Jose, I use the CMSA because all component MSAs in the CMSA include the larger central cities studied here. For Los Angeles and Boston I also use the CMSA because of the stronger relationships among the constituent PMSAs.

5 Some data (e.g., American Housing Survey and some special reports from the US Census) are also available at the "urban place" level. This level includes subcounty local governments but does not cover
} 
Census tracts represent reasonably detailed (or geographically small) enumeration areas, which are designed for the reporting of the decennial censuses. They are geographic areas defined to include similar numbers of residents. Census tracts are not necessarily associated with any economic or politically meaningful boundaries. If one is interested in exploring how suburban local governments either cause or are affected by changes in population or income, census tracts are inappropriate units of analysis. Furthermore, the task of defining consistent boundaries for three US Censuses (1970, 1980 and 1990) is also a major undertaking. Census tracks would have involved many more geographic units, thus making the cost of defining consistent boundaries prohibitive for the current analyses.

Counties represent geographic areas, which have governmental functions, but they vary in size from state to state, and represent substantially larger areas (less detail) than census tracts or minor civil/census county divisions.

I use minor civil division (MCD) or census county division (CCD) aggregations of the data because they describe, in many cases, a politically significant geography and, in all cases, an economically significant geography. ${ }^{6}$ MCDs are primary subcounty governmental or administrative units, most frequently towns and townships; they have legal boundaries as well as governmental functions. In the west and south, however, many states have no subcounty governmental units. In these states, CCDs, statistical entities established cooperatively by the Census Bureau and state and local officials, represent community areas focused on trading centers or land use. They have permanent and "easily described" boundaries, but not governmental functions. CCDs are typically defined so as to include one or more census tracts.

The study of the suburbs of 31 large central cities located in 27 metropoli$\tan$ areas is our focus of interest. The metropolitan areas include a total of 2,975 MCDs/CCDs, based on the STF4B for 1970 and STF3A counts of the US Census. ${ }^{7}$ To assure that the observed trends and relationships in this study are enduring, and are not artifacts of a particular part of a business cycle, I examine data for three de-

all territory in the suburbs. The omitted geographic areas change with changes in place boundaries, making it impossible to create time series data for the period used in this study. Also, the decennial census does not report economic and social data at this level of aggregation.

6 One potential problem is the broad range of population sizes for MCDs and CCDs. MCDs and CCDs are geographic areas, which include populations ranging from 34 persons to almost 8 million persons (New York City). These ranges can be addressed, however, in the statistical analyses by weighting each MCD/CCD by its population size.

7 The 33 largest central cities in 1996 were: New York, NY; Los Angeles, CA; Chicago, IL; Houston, TX; Philadelphia, PA; San Diego, CA; Phoenix, AZ; San Antonio, TX; Dallas, TX; Detroit, MI; San Jose, CA; Indianapolis, IN; San Francisco, CA; Jacksonville, FL; Baltimore, MD; Columbus, OH; El Paso, TX; Memphis, TN; Milwaukee, WI; Boston, MA; Washington, DC; Austin, TX; Seattle, WA; Nashville, TN; Cleveland, OH; Denver, CO; Portland, OR; Fort Worth, TX; New Orleans, LA; Oklahoma City, OK; Tucson, AZ; Charlotte, NC; Kansas City, MO. We exclude Phoenix, San Antonio, El Paso, Oklahoma City, Tucson, and Kansas City because these metropolitan areas had only a handful of civil divisions. San Jose is included in the San Francisco CMSA and Fort Worth is included in the Dallas CMSA. New Orleans is not included because there were too many changes in the boundaries of the suburban divisions to allow comparisons across Census years. Washington DC could not be included in analyses using the 1970 Census data for the same reason. In addition, Atlanta GA, Miami, FL, Minneapolis, MI, St. Louis, MO, and Pittsburgh, PA are added. These latter central cities are within the top 50 in size, but not in the top 33. St. Paul is included, with Minneapolis, as a central city civil division. 
cennial censuses: 1970,1980 and $1990 .^{8}$ Data include times of expansion and low unemployment (1970) and of contraction and high unemployment (1980). When MCDs/CCDs changed boundaries between 1970 and 1990, I combined the divisions necessary to delineate a geographic area whose boundaries did not change. When areas were combined, I created an indicator to record the number of municipalities that were combined in reaching these consistent "municipal" combinations.

\subsection{Characteristics of central cities and suburbs}

Table 1 reports some of the characteristics of MCDs and CCDs for the 31 large central cities and their suburbs included in this study. The first column of numbers in each cell reports unweighted means for municipalities and therefore does not reflect metropolitan population means; the second column of italicized numbers in each cell reports population-weighted means for the civil divisions.

Although $45 \%$ of the central cities are in the northeast or midwest, $86 \%$ of the suburban civil divisions is in these regions. Western MSAs include fewer suburban civil divisions than southern MSAs, which, in turn, include fewer suburban civil divisions than northeastern or midwestern MSAs. The population-weighted percentages reported in the first row cells of Table 1 show that residents of southern MSAs are more likely to reside in central cities. Southern central cities account for $26 \%$ of the central city population in this study, but their suburban civil divisions account for only $12 \%$ of the suburban population. Therefore, the data reported on Table 1 for suburbs include relatively more northeastern and midwestern civil divisions than is the case for central cities.

Table 1 includes data on household income and poverty rates for 1970, 1980 and 1990 for the civil divisions within this study. ${ }^{9}$ The unweighted poverty rate in central

8 To the best of my knowledge, the 1970 MCD/CCD data have not been analyzed prior to this study. The 1970 data were only partially released by the US Census. This analysis is the first to prepare a longitudinal suburban civil division data set for the 1970 through 1990 period.

9 The US Census Bureau defines household income and poverty rates used in this article.

Current household income is the sum of money wages and salaries, net income from self-employment, transfers from government programs, property income (for example, interests, dividends, net rental income), and other forms of cash income (such as private pensions and alimony). Current income does not include capital gains, imputed rents from owner-occupied housing, government or private benefits in-kind (such as food stamps, health care benefits, employer-provided health insurance or other fringe benefits) nor does it subtract taxes, although all of these affect a household's or an individual's consumption levels.

The Census considers persons or households to be poor, or in poverty, if their current incomes are below the threshold poverty income level. The poverty threshold income level is based on a standard developed by the US Social Security Administration in 1963. The level depends solely on monetary income, and does not reflect the fact that many low-income persons receive non-cash benefits such as food stamps, medical care and public housing. Poverty income threshold levels are defined separately by family size and the age of the household head - in each case based on the 1963 cost of an inexpensive, but nutritionally sound, food plan designed by the US Department of Agriculture. This cost of purchasing the food plan is multiplied by three, assuming that households spend one-third of their income on food and is adjusted upward by changes in the Consumer Price Index since 1963. For a household of four persons, the 1989 threshold poverty income level was \$12,675, based on inflationary adjustments to the 1963 level of $\$ 3,128$. For a one-person household under age 65, the 1989 poverty level income was $\$ 6,311$. Because a one-person household requires half the income of a four-person household to 


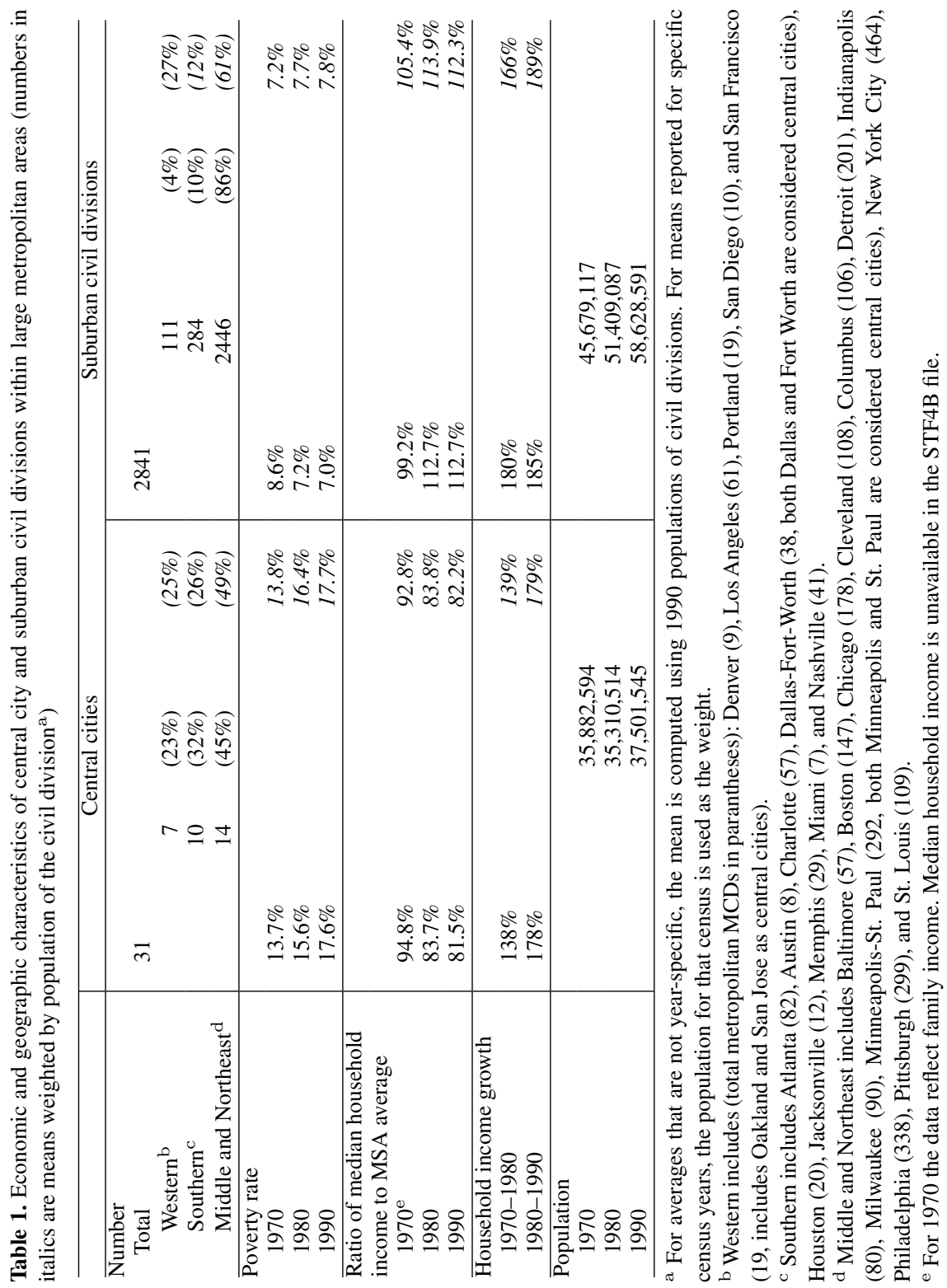


cities increased from $13.7 \%$ to $17.6 \%$ between 1970 and 1990, and the populationweighted poverty rate increased from $13.8 \%$ to $17.7 \%$. The unweighted poverty rate in suburban civil divisions decreases from $8.6 \%$ to $7.0 \%$, but the populationweighted poverty rate increases slightly from $7.2 \%$ to $7.8 \%$. In general in large US MSAs, poverty rates are growing faster - and, therefore, metropolitan poverty is concentrating - in central cities.

The total population of the central cities in this article has grown slightly between 1970 and 1990, but the population of the suburbs has grown more rapidly. As a result, the proportion of metropolitan area residents living in suburban civil divisions increased from $57 \%$ to $62 \%$ over the period. The proportion of poor metropolitan residents residing in the suburbs increased at a slower pace: $40.2 \%$ of the poor in these MSAs resided in the suburbs in 1970, and 41.3\% did so in 1990.

The data for central cities and suburbs in Table 1 indicate that there are substantial economic differences between cities and their suburbs. The table also shows that the size of central cities relative to suburbs and the numbers of suburbs vary by region. Many central cities, especially in the south and west, where the physical capital used in goods and services production is of more recent vintage, have boundaries which encompass most of the population of the metropolitan area. Central cities in the north and midwest, however, include a smaller share of their MSA population. Figure 1 shows, in rank order, the proportion of the population residing in the central cities of the large metropolitan areas included in this study in $1990 .^{10}$

When a central city jurisdiction includes more of the MSA population, there is less competition with suburban jurisdictions for non-poor residents. ${ }^{11}$ The central city has relatively more non-poor to share any additional costs of poor residents, reducing the per-household tax costs and the incentives to locate in the suburbs. There are also fewer options for MSA residents to locate in suburban jurisdictions with fewer poor. As the proportion of the MSA population in the central city rises, concentrations of poverty in suburbs are more likely to arise from factors other than the movement of non-poor residents to avoid taxes.

Only $15 \%$ of the Boston metropolitan area residents live within the Boston city boundaries. At the other extreme the city of Houston includes almost $80 \%$ of the population of its metropolitan area. ${ }^{12}$ In general, the central cities within southern

be above poverty level, there is an equivalence scaling implicit in the poverty rate, which reduces the necessary per capita income as household size increases.

10 These data reflect the proportions of the metropolitan population residing in the geographic areas defined as central cities in the database used in our analysis. I define consistent geographic boundaries for central cities from 1970 to 1990 . While the boundaries are the 1990 ones for most central cities and very close to the 1990 boundaries for the rest, they do not always match exactly. In some cases, suburban civil divisions may be included, as described below, in order to define a consistent set of boundaries across the time period. For this reason, population counts may differ from those published for the 1990 boundaries of these areas.

11 The amount of competition between central cities and suburban jurisdictions for residents is also affected by the number of suburban jurisdictions. The number of suburban jurisdictions in these metropoli$\tan$ areas is, however, significantly and negatively correlated with the central city share of metropolitan population $(-0.49)$.

12 This percentage overstates the share of the MSA population within the city of Houston in 1990. To maintain the same geographic boundaries for the city between 1970 and 1990, it was necessary 


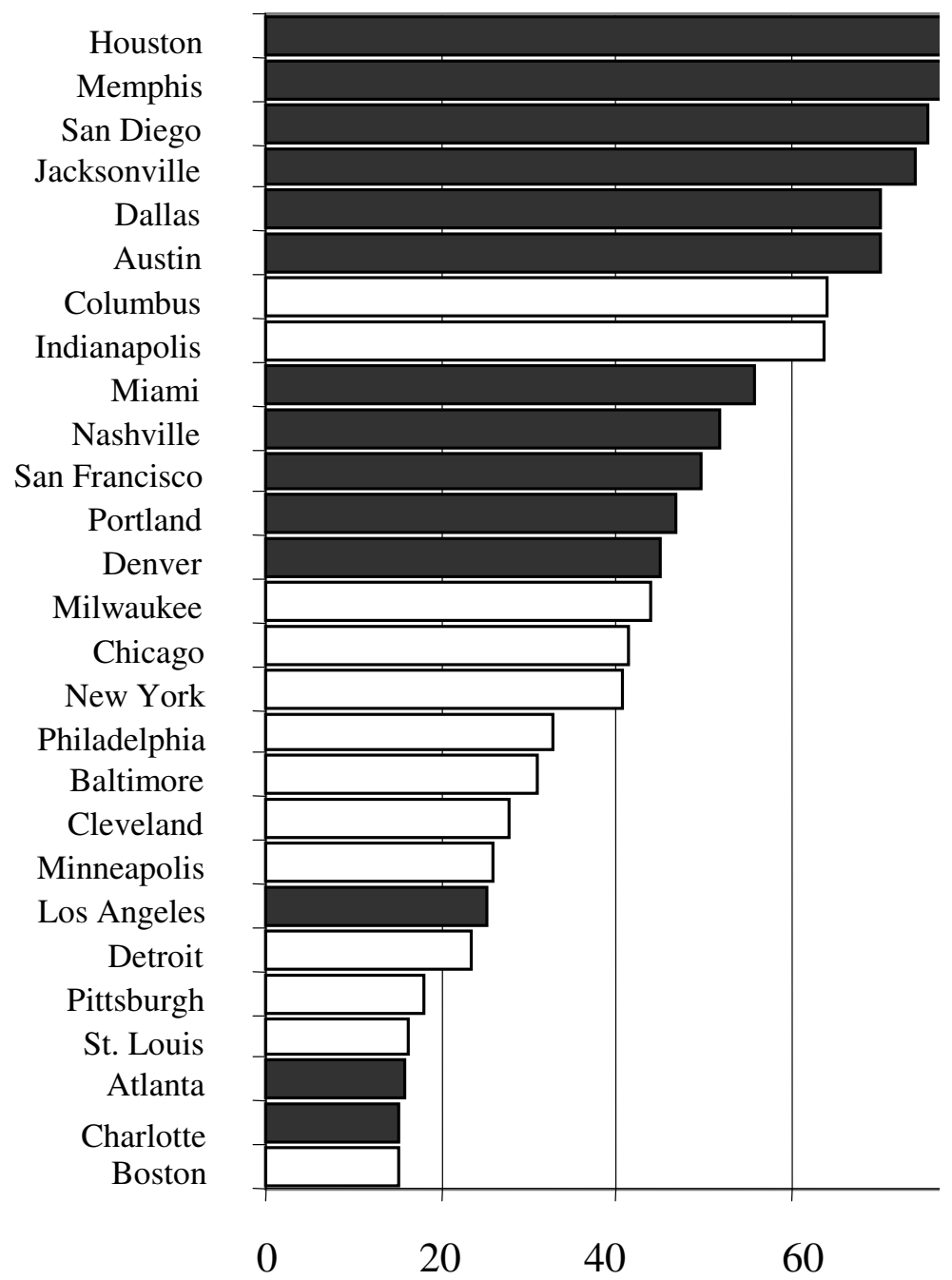

Fig. 1. Central city population as percentage of the metropolitan area, with South and West in black, and Northeast and Midwest in white

and western metropolitan areas (indicated in Fig. 1 and in the remaining figures by darker shaded bars) include a larger share of the metropolitan population than do central cities in the northeast or the midwest (indicated by the lighter shaded bars).

The regional differences in MSAs include more than the relative size of the central city and the number of suburbs. The poverty differences between cities and suburbs shown in Table 1 also vary by region. Figure 2 shows the proportion of the MSA population living in suburban civil divisions with poverty rates that are $90 \%, 75 \%$, and $50 \%$ as high as the poverty rates for their central cities. The

to include the entirety of some suburban Census county divisions that had a portion of their territory annexed by the city of Houston between 1970 and 1990. 


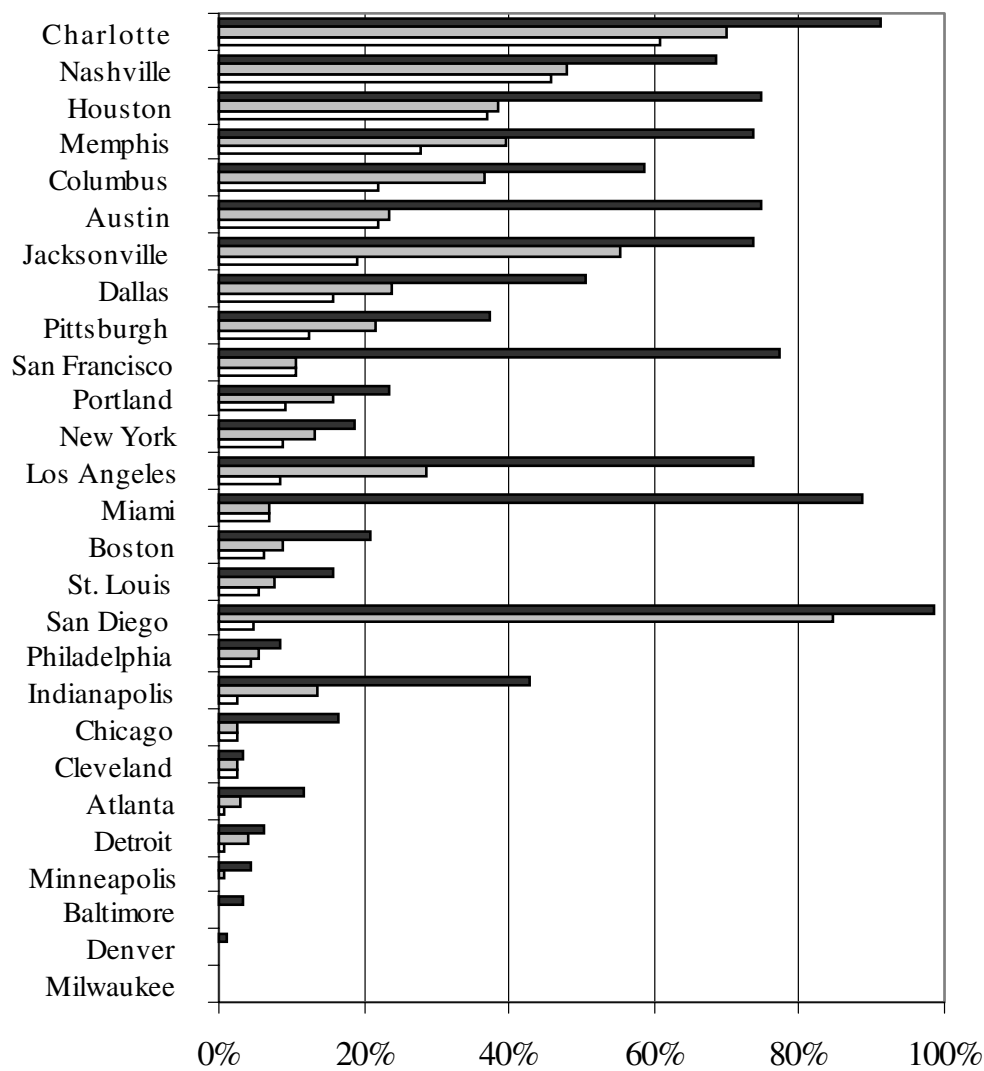

Fig. 2. Percentage of the suburban population residing in civil divisions, with poverty at $90 \%$ (white), $75 \%$ (grey), and $50 \%$ (black) of the central city poverty

metropolitan areas are listed on the figure according to the proportion of their suburban populations living in civil divisions whose poverty rates are at least $90 \%$ of the central city poverty rate. The MSAs with the largest proportion of the suburban population living in civil divisions with poverty rates near to that of their central cities are in the south (Charlotte, Nashville, Houston, Memphis). With the exception of Charlotte, these central cities include most of their MSA population. In these MSAs, suburban jurisdictions are not strongly advantaged in competing with the central city for non-poor residents.

At the other extreme the MSAs with very small proportions of the suburban population (and in some cases none) residing in civil divisions with poverty rates even as low as half of the central city's include Milwaukee, Denver, Baltimore, Minneapolis, Indianapolis, Detroit, Atlanta, Cleveland, Chicago, and Philadelphia. Other than Denver and Atlanta, these MSAs are located in the midwestern and northeastern United States.

In sum, although poverty rates have increased more in the central cities of large US MSAs than in their suburbs, there are differences among MSAs that show 
strong regional patterns. The large MSAs in the midwestern and northeastern US have relatively more of their population in their suburbs and the income differences between their central city residents and their suburban residents are larger than for the MSAs in the south and west.

\subsection{General approach}

To examine whether poorer households are becoming relatively more concentrated among some suburban municipalities for these 27 large MSAs, I calculate two general indicators of relative concentration by using two different variables to measure changes in income levels of municipality residents: poverty rates and the ratio of median household income in the municipality to the MSA median.

We now analyze whether the coefficient of variation, a general indicator of the relative variability in the poverty rate (or household median income) across suburbs, is changing over time. The coefficient of variation is the standard deviation of a variable divided by its mean; it reflects variation independently from the units of the characteristic being measured. When the coefficient of variation for a characteristic increases, the variation in the characteristic is increasing across the observation points. If the coefficient of variation of the poverty rate is increasing, the relative variability of poverty across municipalities within the MSA is increasing, indicating that poverty is growing relatively within some suburban municipalities while declining relatively among others. ${ }^{13}$

We next measure the effect of the 1970 poverty rate or median household income level on the 1990 levels and on the rate of growth of those characteristics for each MSA, by civil division. If there is a greater relative concentration of poverty among the suburbs, then those jurisdictions with higher 1970 poverty rates are expected to have higher 1990 poverty rates. If this were not the case, then there is no evidence of a relative increase in the concentration of poverty. This indicator of concentration is "rooted in history", in that it tests whether the poorer municipalities become poorer and the richer municipalities become richer over time.

\section{Indicator I: The coefficient of variation}

Table 2 shows the changes in the means of the coefficients of variation for suburban municipality poverty rates and median household income for the 27 MSAs included in this study between 1990 and 1980 and 1990 and 1970. There is relatively greater variation among suburban municipalities in the poverty rate than there is for median household income, as reflected by the larger coefficients of variation for the poverty rates. The 1990 means of the coefficients of variation for both the poverty rate and for household income are not statistically different from the 1980 means. The 1990 mean of the coefficients of variation for household income is also not statistically

13 I have chosen not to use a spatial index such as the $G$-statistic because the location of suburban municipalities in relation to each other is not expected to affect the relationship between poverty and the program expenses or tax revenues of local jurisdictions. 
Table 2. Changes in intra-metropolitan coefficients of variation among suburban municipalities: poverty rates and median household income, 1970-1990

\begin{tabular}{lcc}
\hline & Poverty rate & Median household income \\
\hline 1990 coefficient of variation & 0.584 & 0.270 \\
Difference from 1980 & 0.075 & 0.048 \\
$t$-statistic & 1.24 & 0.87 \\
Difference from 1970 & 0.109 & 0.020 \\
$t$-statistic & 2.04 & 0.76 \\
\hline
\end{tabular}

different from the 1970 mean. However, the 1990 mean of the coefficient of variation for the poverty rate is statistically greater than the 1970 mean, revealing an increasing concentration of poverty in the suburbs. ${ }^{14}$

Figure 3 shows the 1970, 1980 and 1990 patterns of coefficients of variation for the poverty rates of the suburban municipalities for each of the 27 MSAs. The MSAs are graphed in ascending order of magnitude of change in their coefficients of variation between 1970 and 1990. By this measure most MSAs experienced relative increases in the concentration of poverty among their suburbs. Philadelphia's suburbs experienced the greatest increase in concentration between 1970 and 1990 among the suburbs of the large MSAs. Detroit, Cleveland, Austin, Boston, Chicago, Denver, New York, and St. Louis had the next highest rates of increase in the concentration of their suburban poverty rates. Minneapolis, Miami, San Diego, Houston, Portland, and San Francisco witnessed convergence in the poverty rates of their suburbs, as measured by the coefficient of variation. The suburban municipalities in the northeastern and midwestern MSAs generally experienced greater increases in the concentration of poverty than suburban municipalities in the south and west.

We see in Fig. 4 the 1970, 1980 and 1990 coefficients of variation for the ratio of the suburban municipality's median household income to the MSA median for each of the 27 MSAs. As with Fig. 3 the MSAs are graphed in ascending order of magnitude of their changes in coefficients of variation between 1970 and 1990. As noted above in the discussion of Table 2, and the average rates for the 27 MSAs, there is far less relative spatial variation in median household income than in poverty rates. We see that the coefficients of variation for relative median household income are much lower than the coefficients of variation for poverty rates.

Comparisons of Figs. 3 and 4 illustrate important differences in the coefficients of variation for poverty rates and median household income. The MSAs with the largest coefficients of variation for poverty - and with the greatest rate of increase in the coefficients - are frequently not those with the largest coefficients of variation for median household income. The southern and western MSAs had greater relative increases in concentration of household income in their suburbs than those

${ }^{14}$ Within each MSA, the poverty rate and median household income for each municipality is weighted by population in order to determine the coefficient of variation for the MSA. To compute the mean for the 27 MSAs, however, an unweighted mean (which simply averages the coefficient of variation for each MSA) is computed. 


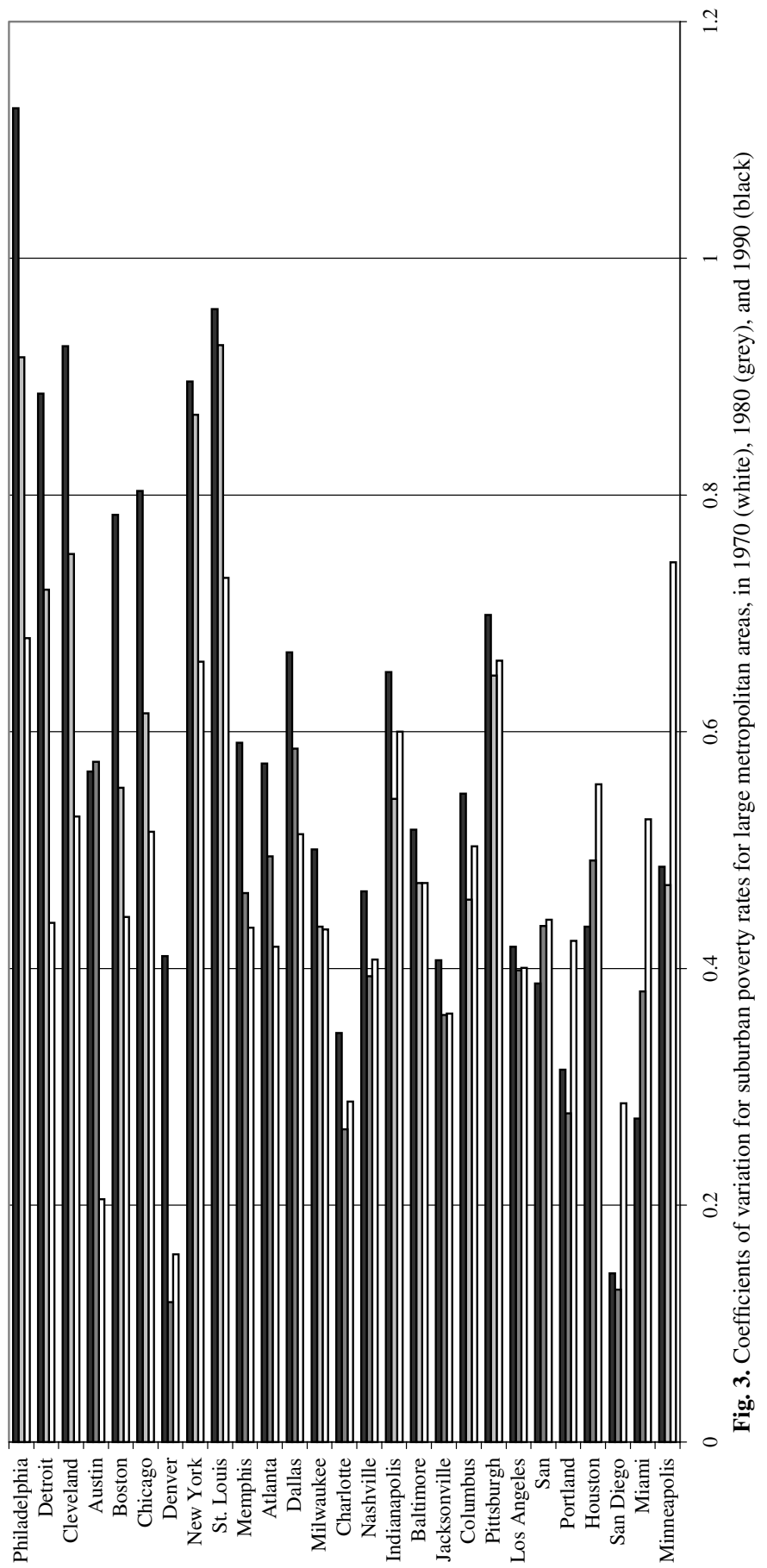




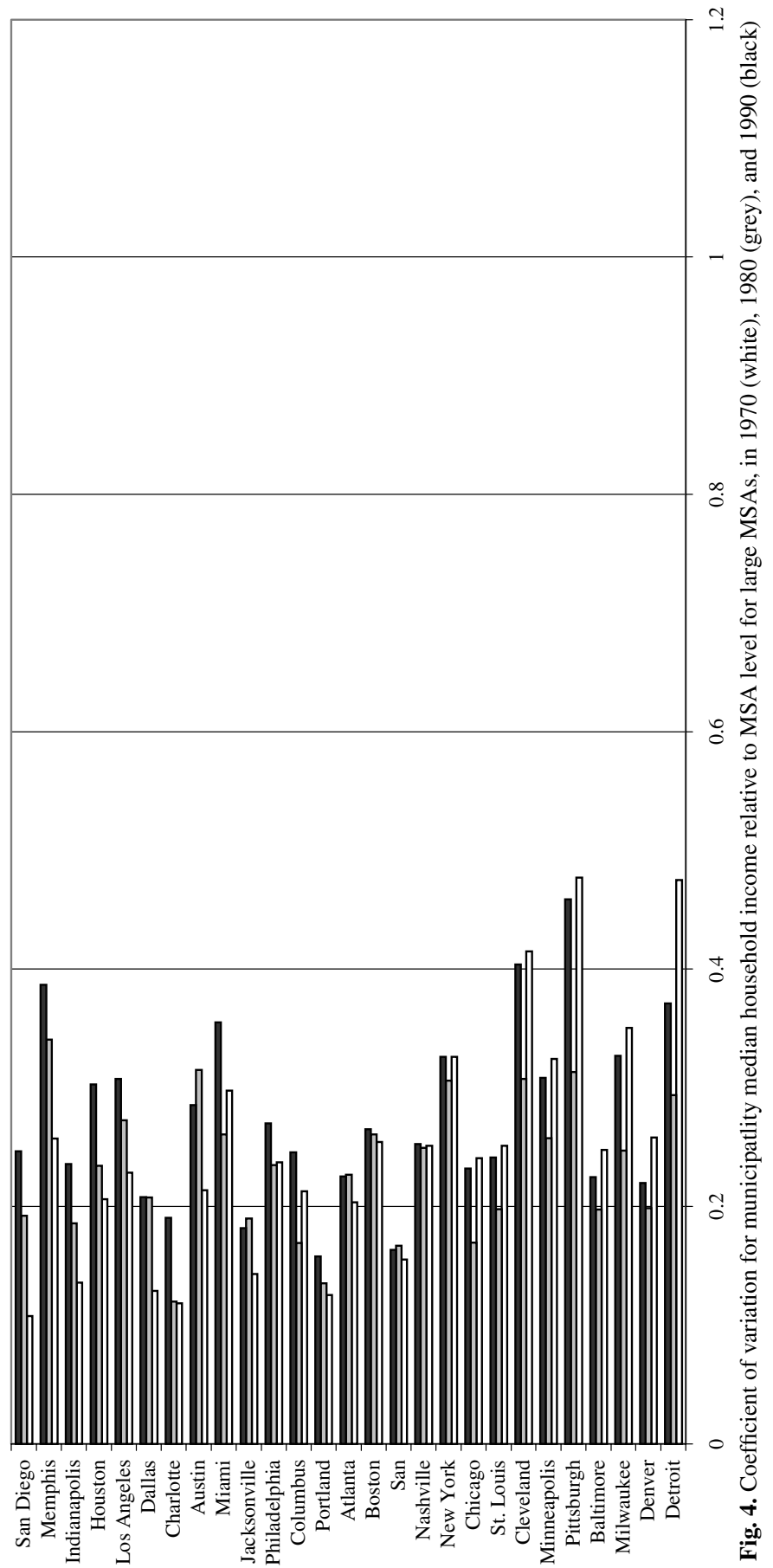


experienced by the midwestern and northeastern MSAs. In contrast, the suburban municipalities in the northeastern and midwestern MSAs generally experienced relatively greater increases in the concentration of poverty than suburban municipalities in the south and west.

The differences are mostly due to two considerations. Firstly, the general increase in the inequality of the household income distribution between 1970 and 1990 means that the middle of the distribution (i.e., the median) does not change as much as the tails of the distribution (the proportions in the poorest and highest income groups). Therefore, measures of the tail of the distribution, such as the poverty rate, will be more sensitive to income change than measures of the middle, such as the median household income. Secondly, poverty and median household income measure different phenomena. To the extent that income shifts among suburbs are occurring with changes in the locations of poverty households relative to higher income households in the MSA, the poverty rate measure will be more sensitive to municipality income changes. However, it is clear that in some MSAs, particularly the newer ones in the south and west, poverty rates - although not changing in the suburbs - are increasing in the central cities. Furthermore, non-poor households in these MSAs are suburbanizing differently depending on their own incomes. The higher income households are concentrating within different suburban locations than middle income households.

For example, Detroit has had the greatest decrease (among the 27 MSAs in Fig. 4) in its coefficients of variation for median household income among its suburbs while having had the second greatest increase in its coefficients of variation for poverty within its suburbs (Fig. 3). Detroit's suburbs experienced simultaneous increases in poverty and in their relative household median incomes. Between 1970 and 1990, the average poverty rate in the suburbs increased from 5.2 to $6.9 \%$, while the average suburban municipality saw its median household income rise from $108 \%$ to $114 \%$ of the MSA median. ${ }^{15}$ The convergence in the suburban coefficients of variation for household income occurred because the standard deviation of the household income measure changed little (from 33.2 to 34.2). The standard deviation of the poverty rate almost doubled, however, (from 3.3 to 6.1). Some suburbs (Highland Park, River Rouge, Hamtramck, Ecorse, Pontiac, Royal Oak, Inkster, Port Huron City, and Lapeer) had very large increases in poverty, while 98 of the 200 suburbs - housing almost a third of suburban residents - experienced no change or had a decrease in poverty rates. Income is becoming relatively more concentrated in Detroit suburbs because of the increasing concentration of the poor.

San Diego is also an example of an MSA with very different outcomes for poverty rates and median household income. For the San Diego MSA, however, the differences were the opposite of Detroit. San Diego experienced a relative decrease in the concentration of poverty among its suburbs, but the greatest (relative to the other MSAs) increase in the spatial concentration of median income among its suburbs. For newer MSAs, such as those in the west and south, this paradox occurs because the poor are still concentrating in the central city. The concentration of the

15 This occurs because MSA poverty is increasing overall, while the median household income of residents of the city of Detroit is decreasing relative to the suburbs. 
poor in the city of San Diego is occurring because higher income households are increasingly more likely to reside in the suburbs, and within specific suburbs, thereby increasing the spatial concentration of overall income, but not poverty, among the suburbs. Between 1970 and 1990, the poverty rate in the central city of San Diego increased from $10 \%$ to $11.8 \%$, while poverty rates decreased in every suburb, with the exception of the suburb with the lowest 1970 poverty rate (Pendleton) where poverty increased from $2.6 \%$ to $7.0 \%$. Central city households had a median income in 1970 that was $102 \%$ of the MSA median. By 1990 central city median income was slightly below the MSA level (99\%), and several suburbs experienced substantial relative growth both in their population and median household incomes. The population of the suburbs grew from $16 \%$ to $25 \%$ of the MSA between 1970 and 1990. The suburbs of Jamul and Ramona, for example, had median incomes at $97 \%$ and $96 \%$ of the MSA median in 1970, but their populations grew 3.4 and 4.7 fold (respectively) by 1990 . These population increases came from growth in the number of higher income households as median household incomes in 1990 grew to $150 \%$ and $124 \%$ (respectively) of the MSA median. Income is becoming more concentrated in the San Diego suburbs because higher income households are less likely to reside in the central city and more likely to select particular suburbs.

In sum, the coefficients of variation for poverty rates tend to increase (relatively) more among suburbs of the older MSAs in the north and midwest, as indicated by the MSAs listed on the left hand side of Fig. 3. The coefficients of variation for household income tend to increase more among suburbs of the newer MSAs in the south and west, as indicated by the MSAs listed on the left hand side of Fig. 4. MSAs are ranked differently on the two figures for two reasons. Suburbs of the older MSAs, where metropolitan-wide poverty rates are increasing, are witnessing an increasing concentration of income as reflected in poverty rates. Suburbs of the newer MSAs, where higher income households are increasingly more likely to reside in suburbs rather than the central city, are not experiencing much change in poverty rates, but are experiencing changes in median household income, which is sometimes concentrated in particular suburbs.

\section{Indicator II: Effect of 1970 level}

In this section I provide another formulation of an index of changes in the concentration of poverty between 1970 and 1990 within the entire metropolitan area (including the central city) and within the suburbs only for each MSA in the study. The index represents the relationship between a civil division's poverty rate in 1970 and the change in its poverty rate over the next twenty years. These indexes of metropolitan concentration of poverty or median household income are regression coefficients. The absolute change in the poverty rate between 1990 and 1970 for the civil division is regressed on the 1970 poverty rate and the coefficient is reported in Table 3. (As with the other statistical procedures reported here, the regression analyses has used 1990 population weights for each civil division.) Two regression analyses in particular are performed: 
Table 3. Dependent variable: absolute change in municipal poverty rate, 1970-1990

\begin{tabular}{|c|c|c|c|c|}
\hline \multirow[b]{2}{*}{$\begin{array}{l}\text { Coefficient of } 1970 \\
\text { poverty rate interacted with MSA }\end{array}$} & \multicolumn{2}{|c|}{ Entire MSA } & \multicolumn{2}{|c|}{ Suburbs only } \\
\hline & Coefficient & $t$-statistic & Coefficient & $t$-statistic \\
\hline Atlanta & -0.390 & -6.713 & -0.830 & -15.109 \\
\hline Austin & -1.043 & -6.542 & -0.029 & -0.13 \\
\hline Baltimore & 0.238 & 3.994 & -0.741 & -5.732 \\
\hline Boston & 0.366 & 5.319 & 0.429 & 4.81 \\
\hline Charlotte & -0.764 & -4.274 & -0.752 & -5.071 \\
\hline Chicago & 0.617 & 15.801 & 0.696 & 8.211 \\
\hline Cleveland & 0.799 & 11.707 & 0.683 & 3.841 \\
\hline Columbus & -0.206 & -1.249 & -0.437 & -3.055 \\
\hline Dallas & -0.318 & -3.229 & -0.368 & -4.517 \\
\hline Denver & 0.090 & 0.7 & -1.099 & -5.586 \\
\hline Detroit & 1.323 & 24.01 & 0.524 & 6.364 \\
\hline Houston & -0.833 & -9.653 & -0.723 & -10.011 \\
\hline Indianapolis & -0.076 & -0.388 & -0.558 & -3.117 \\
\hline Jacksonville & -0.740 & -4.525 & -0.562 & -3.983 \\
\hline Los Angeles & 0.092 & 2.227 & -0.118 & -3.155 \\
\hline Memphis & -0.930 & -13.857 & -0.725 & -10.34 \\
\hline Miami & -0.071 & -0.792 & -0.305 & -2.666 \\
\hline Milwaukee & 1.390 & 11.117 & -0.585 & -2.075 \\
\hline Minneapolis & 0.075 & 0.842 & -0.777 & -7.867 \\
\hline Nashville & -0.816 & -7.152 & -0.660 & -6.621 \\
\hline New York & 0.424 & 16.776 & 0.213 & 6.566 \\
\hline Philadelphia & 0.483 & 10.333 & 0.290 & 4.648 \\
\hline Pittsburgh & 0.189 & 2.748 & 0.061 & 0.97 \\
\hline Portland & -0.036 & -0.206 & -0.466 & -2.599 \\
\hline St Louis & 0.262 & 4.898 & 0.240 & 3.837 \\
\hline San Diego & -0.841 & -3.608 & -0.660 & -3.322 \\
\hline San Francisco & -0.039 & -0.589 & -0.286 & -3.126 \\
\hline
\end{tabular}

Suburbs Only (estimated for all suburban civil divisions):

$$
\text { PovRate }_{j, 90}-\text { PovRate }_{j, 70}=a_{0}+a_{1} K+a_{2, k} K^{*} \text { PovRate }_{j, 70}+e
$$

Entire MA (estimated for all suburban and central city civil divisions):

$$
\text { PovRate }_{j, 90}-\text { PovRate }_{j, 70}=b_{0}+b_{1} K+b_{2, k} K^{*} \text { PovRate }_{j, 70}+e
$$

where:

$K$ is a dummy variable indicating the metropolitan area for each $j$ civil division.

The coefficients $a_{2, k}$ and $b_{2, k}$ (values defined for each $K$ metropolitan area) measure the tendency for poverty rates to "regress to the mean;" if the values are 
Table 3. (continued)

\begin{tabular}{|c|c|c|c|c|}
\hline & \multicolumn{2}{|c|}{ Entire MSA } & \multicolumn{2}{|c|}{ Suburbs only } \\
\hline & Coefficient & $t$-statistic & Coefficient & $t$-statistic \\
\hline \multicolumn{5}{|l|}{ MSA Intercepts } \\
\hline Atlanta & -13.219 & -4.448 & 15.151 & 2.985 \\
\hline Austin & 16.135 & 5.617 & -9.231 & -1.834 \\
\hline Baltimore & -17.990 & -6.095 & 12.541 & 2.457 \\
\hline Boston & -18.260 & -6.218 & 6.756 & 1.332 \\
\hline Charlotte & -9.533 & -2.57 & 15.461 & 2.849 \\
\hline Chicago & -17.678 & -6.105 & 7.370 & 1.459 \\
\hline Cleveland & -18.335 & -6.215 & 7.476 & 1.464 \\
\hline Columbus & -12.504 & -3.709 & 12.504 & 2.387 \\
\hline Dallas & -11.661 & -3.798 & 10.742 & 2.098 \\
\hline Denver & -15.598 & -5.026 & 15.492 & 2.987 \\
\hline Detroit & -20.327 & -6.978 & 8.360 & 1.653 \\
\hline Houston & -3.189 & -1.03 & 16.907 & 3.271 \\
\hline Indianapolis & -14.184 & -4.252 & 11.516 & 2.205 \\
\hline Jacksonville & -8.850 & -2.153 & 9.811 & 1.688 \\
\hline Los Angeles & -14.191 & -4.882 & 12.301 & 2.437 \\
\hline Memphis & 0.538 & 0.163 & 16.078 & 2.867 \\
\hline Miami & -10.141 & -3.252 & 16.706 & 3.237 \\
\hline Milwaukee & -21.885 & -7.178 & 10.862 & 2.09 \\
\hline Minneapolis & -14.643 & -4.97 & 12.957 & 2.558 \\
\hline Nashville & -7.488 & -2.215 & 13.246 & 2.481 \\
\hline New York & -18.520 & -6.417 & 7.748 & 1.537 \\
\hline Philadelphia & -18.989 & -6.517 & 7.184 & 1.422 \\
\hline Pittsburgh & -15.407 & -5.18 & 10.420 & 2.054 \\
\hline Portland & -15.041 & -4.513 & 12.382 & 2.36 \\
\hline St Louis & -16.873 & -5.748 & 8.603 & 1.699 \\
\hline San Diego & -6.447 & -1.72 & 15.295 & 2.774 \\
\hline$\underline{\text { San Francisco }}$ & -15.879 & -5.398 & 10.998 & 2.163 \\
\hline Adjusted $R^{2}$ & 0.525 & & 0.434 & \\
\hline$N$ & 2872 & & 2841 & \\
\hline
\end{tabular}

negative, then those civil divisions with higher poverty rates for 1970 experienced less of an increase in poverty by 1990 than those with lower 1970 poverty rates. If $b_{2, k}$ is positive, poverty rates are then becoming more concentrated within the metropolitan area. If $a_{2, k}$ is positive, then poverty rates are becoming more concentrated within some suburbs.

The two indicators of relative changes in concentration (the coefficient of variation, discussed in Sect. 3, and the coefficient of the regression of changes in the level of a variable on first-period levels of a variable) do not necessarily yield identical results. To the extent that increases in the concentration of poverty (or another characteristic) are not related to historical spatial patterns of poverty (that is, there 
is an increasing difference between poorest and richest regions, but poorest and richest regions in the second period are different from those in the first period), then the coefficient of variation could show an increasing concentration of poverty, while the regression of prior poverty on current poverty would show convergence.

The results of the regressions of changes in poverty rates between 1970 and 1990 are listed in Table 3 and portrayed graphically in Fig. 5. In Fig. 5 MSAs are sorted in ascending order of their indices of concentration of suburban poverty. To interpret the results, consider the case of Milwaukee, where the "entire MSA" index (polka dot light bar) is 1.39. The index value means that a civil division in the Milwaukee MSA with a 1970 poverty rate, which was one percentage point higher than that of another division, experienced a growth in poverty between 1970 and 19901.39 percentage points higher. More generally, if the index is positive, there is a growing concentration of poverty in the area because poverty is growing more rapidly in initially high poverty civil divisions and less in low poverty divisions. Furthermore, the concentration is growing more rapidly as the index increases in value. If the index is greater than one, the concentration of poverty is accelerating. If the index is negative, however, poverty is deconcentrating, or becoming more evenly spread across the geographic area. When the central city of Milwaukee is removed from the analysis and we examine only the concentration of poverty in the suburbs, the index is -0.59 (light shaded bar). For Milwaukee, there is an extreme concentration of poverty within the central city. Among Milwaukee's suburbs poverty is becoming more evenly distributed or is de-concentrating.

There are eight MSAs for which poverty is relatively concentrating in the suburbs (that is, the eight at the right-hand side of the figure where the shaded bar is positive). Except for Chicago and Boston, the rate of concentration is greater in the central city than in the suburbs (the polka dot MSA bar is greater than the shaded suburbs-only bar on the figure). The eight MSAs, which are experiencing concentrating poverty among their suburbs, include seven of the nine MSAs identified in Fig. 3 as experiencing increasing levels of concentration of poverty using the coefficient of variation as the index.

In the southern and western MSAs, where the central cities include more of the MSA population, and where there is less overall differential between central city and suburban poverty, there is evidence of a relative de-concentration of poverty among local jurisdictions. Fourteen MSAs - Austin, Memphis, San Diego, Houston, Nashville, Charlotte, Jacksonville, Atlanta, Dallas-Fort Worth, Columbus, Indianapolis, Miami, San Francisco, and Portland - had a relative de-concentration of poverty within the MSA between 1970 and 1990 (as indicated by the lightly shade MSA bars being negative). In all of these MSAs, there was also a de-concentration among the suburbs. Furthermore, these 14 include the 12 MSAs with the highest proportions of the population residing in the central city (Fig. 1). In the Atlanta, Dallas-Fort Worth, Columbus, Indianapolis, Miami, San Francisco, and Portland MSAs, the de-concentration was greater for the "suburbs only" than for the entire MSA (as indicated by the more darkly shaded bar being "more negative" than the more lightly shaded bar on the graph). In these MSAs a relative concentration of poverty within the central city relative to the suburbs was therefore observed. 


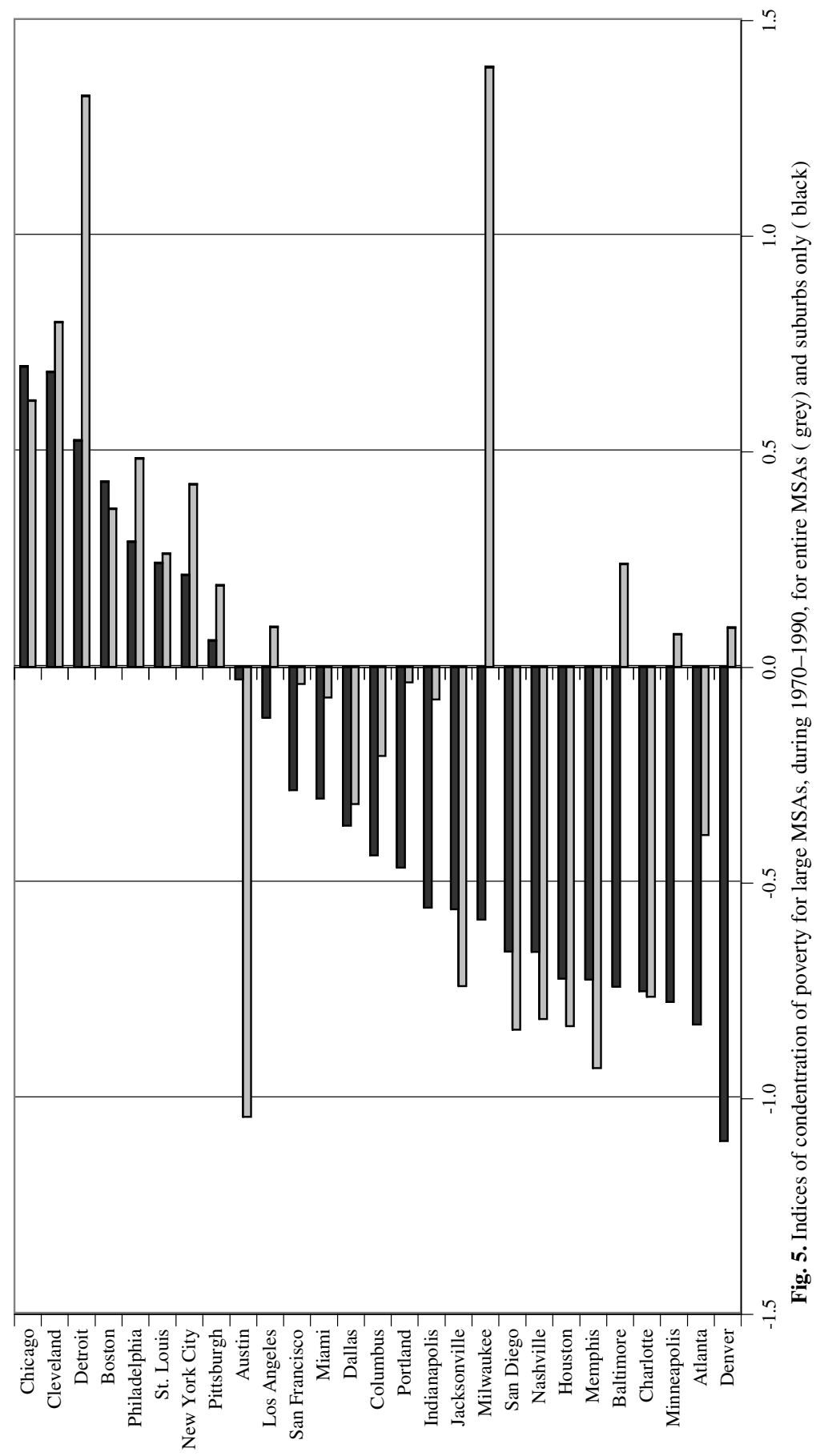


For the remaining MSAs - Milwaukee, Detroit, Cleveland, Chicago, Philadelphia, New York City, Boston, St. Louis, Baltimore, Pittsburgh, Los Angeles, Denver, and Minneapolis - poverty concentrated within some civil divisions. For Minneapolis, Denver, Los Angeles, Baltimore, and Milwaukee, the concentration was entirely within the central city, because poverty became more concentrated (index is positive) for the "entire MSA," but became less concentrated (index is negative) within the "suburbs only." For all but Boston and Chicago, the concentration within the "suburbs only" was less than for the entire MSA. This result implies that, with the exception of Boston and Chicago, the concentration of MSA poverty was greater within the central city for all MSAs that experienced an increase in the spatial concentration of poverty in suburbs.

There is, nonetheless, evidence of increasing concentrations of poverty within the suburban jurisdictions of Detroit, Cleveland, Chicago, Philadelphia, New York, Boston St. Louis, and Pittsburgh. These MSAs all show a positive index for the "suburbs only" on Table 3 and Fig. 5. Furthermore, in Cleveland, Chicago, Boston, and St. Louis, the "entire MSA" and the "suburbs only" indexes are close, indicating that the rate of concentration of poverty within the suburbs rivaled that of the levels of concentration within the central city relative to the suburbs. These MSAs are among those with the highest central city poverty rates, and the lowest suburban rates. While the time trend is showing concentration of poverty within the suburbs, levels of poverty remain very different between even the poorest of the suburbs and their central cities for these MSAs.

Table 4 and Fig. 6 present the same index of concentration as in Table 3 and Fig. 5, but represent household income rather than poverty. The MSAs showing the most de-concentration are in the south and west (Austin, Memphis, San Diego, Houston, and Dallas). The areas showing the greatest concentration are more likely to be in the northeast and midwest (Denver - being an exception, Milwaukee, New York, Chicago, San Francisco - another exception, Pittsburgh, Cleveland, Boston, Philadelphia, and Baltimore). As was noted with the discussion of the coefficients of variation reported in the previous section, there is a more even distribution of household income across civil divisions within MSAs than there is of poverty households.

As in the case of poverty, there are differences in the measured changes in the spatial concentration of household income among suburbs between the coefficient of variation (Fig. 4) and the regression of change in household income on 1970 levels (Fig. 6). One of the more striking examples of this anomaly is Charlotte. Figure 6 shows that Charlotte, among all MSAs, has the greatest de-concentration of household income in its suburbs, while Fig. 4 indicates that Charlotte has an increase in concentration of household income in its suburbs. Both computations are correct, and the differences illustrate an important difference in the two measures of concentration. Charlotte is an MSA where on average, between 1970 and 1990, the poorer suburbs in 1970 experienced greater relative increases in household income than the richer suburbs. Therefore, a regression of the change in median household income on the 1970 levels shows a "regression to the mean" or convergence. Nonetheless, the overall distribution of household income among suburbs became more disparate. For example, the lowest income suburb in 1970, McConnells, had 


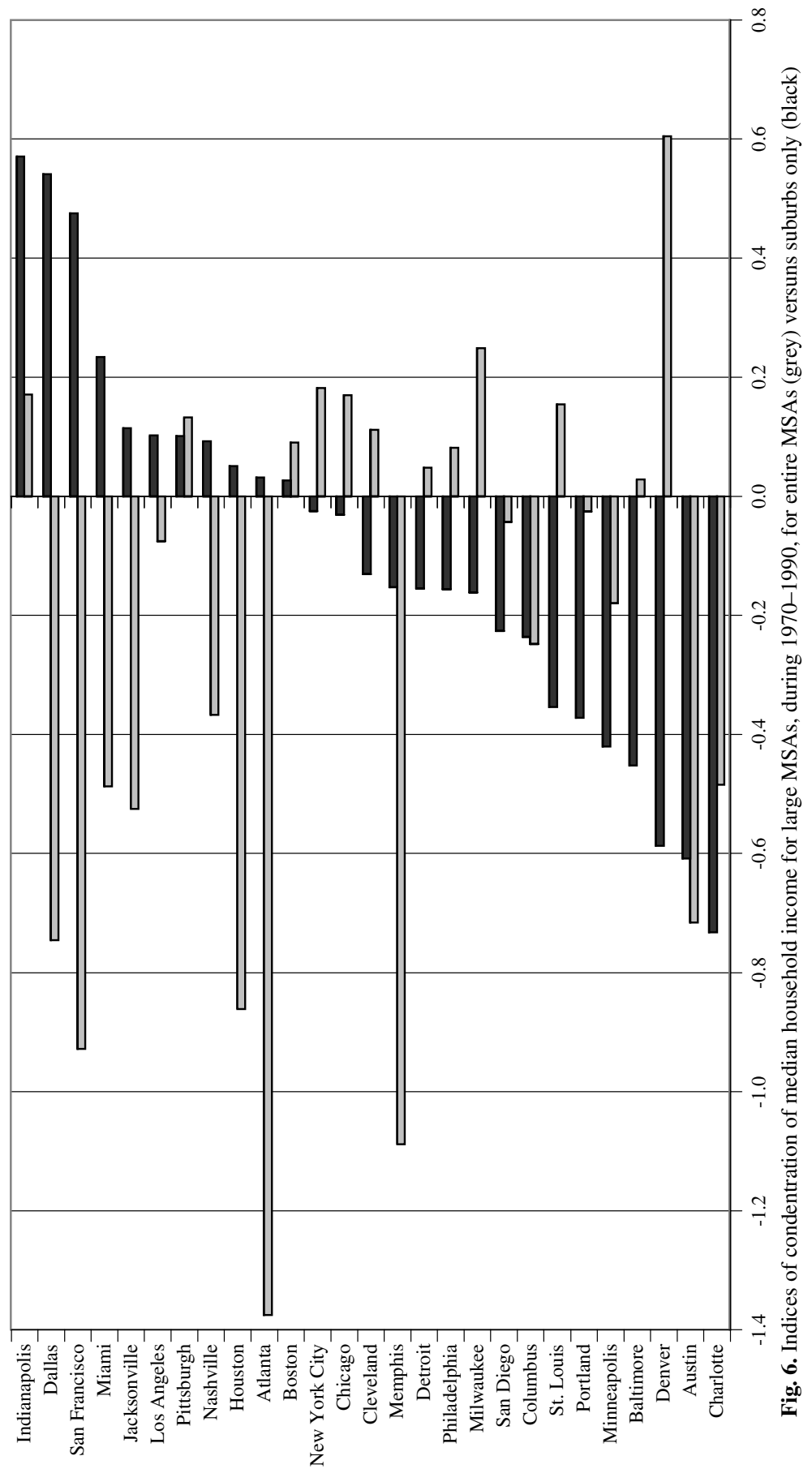


Table 4. Dependent variable: absolute change in household median income as proportion of MSA median, 1970-1990

\begin{tabular}{|c|c|c|c|c|}
\hline \multirow[b]{2}{*}{$\begin{array}{l}\text { Coefficient of } 1970 \\
\text { household income ratio } \\
\text { interacted with MSA }\end{array}$} & \multicolumn{2}{|c|}{ Entire MSA } & \multicolumn{2}{|c|}{ Suburbs only } \\
\hline & Coefficient & $t$-statistic & Coefficient & $t$-statistic \\
\hline Atlanta & -0.716 & -5.40 & -0.608 & -5.85 \\
\hline Austin & -1.375 & -4.70 & 0.031 & 0.07 \\
\hline Baltimore & 0.028 & 0.28 & -0.452 & -4.54 \\
\hline Boston & 0.090 & 1.23 & 0.026 & 0.43 \\
\hline Charlotte & -0.484 & -1.98 & -0.732 & -1.83 \\
\hline Chicago & 0.170 & 3.34 & -0.031 & -0.66 \\
\hline Cleveland & 0.112 & 1.36 & -0.131 & -1.70 \\
\hline Columbus & -0.248 & -1.51 & -0.236 & -1.84 \\
\hline Dallas & -0.745 & -4.19 & 0.541 & 2.68 \\
\hline Denver & 0.605 & 2.32 & -0.587 & -1.90 \\
\hline Detroit & 0.048 & 0.92 & -0.155 & -3.51 \\
\hline Houston & -0.861 & -3.99 & 0.050 & 0.23 \\
\hline Indianapolis & 0.171 & 0.49 & 0.571 & 2.05 \\
\hline Jacksonville & -0.525 & -0.95 & 0.114 & 0.24 \\
\hline Los Angeles & -0.076 & -1.25 & 0.102 & 2.12 \\
\hline Memphis & -1.088 & -4.36 & -0.152 & -0.38 \\
\hline Miami & -0.487 & -1.46 & 0.234 & 0.86 \\
\hline Milwaukee & 0.249 & 2.00 & -0.161 & -1.38 \\
\hline Minneapolis & -0.180 & -1.75 & -0.420 & -4.93 \\
\hline Nashville & -0.367 & -2.11 & 0.092 & 0.60 \\
\hline New York & 0.182 & 5.88 & -0.025 & -0.96 \\
\hline Philadelphia & 0.081 & 1.37 & -0.156 & -3.03 \\
\hline Pittsburgh & 0.132 & 1.67 & 0.102 & 1.64 \\
\hline Portland & -0.026 & -0.08 & -0.372 & -1.42 \\
\hline St Louis & -0.043 & -0.47 & -0.226 & -2.92 \\
\hline San Diego & -0.928 & -2.57 & 0.475 & 0.76 \\
\hline San Francisco & 0.154 & 1.06 & -0.354 & -2.78 \\
\hline
\end{tabular}

a median household income which was $66.1 \%$ of the MSA median in 1970, but grew (or regressed toward the mean) to $87.7 \%$ by 1990 . Other suburbs replaced McConnells at the bottom, however. Salisbury, became the lowest income in 1990 with a median household income which was $69.7 \%$ of the MSA median, down from a midrange of $91.7 \%$ in 1970 . For Charlotte, there was increasing concentration of household income (as shown in Fig. 4), but the increasing concentration was not tied closely to the municipalities prior ranking (Fig. 6).

In sum, the indices of relative concentration for poverty rates tend to increase more among suburbs of the older MSAs in the north and midwest, as indicated by the MSAs listed on the left-hand side of Fig. 5. As with the coefficients of variation, 
Table 4 (continued)

\begin{tabular}{|c|c|c|c|c|}
\hline \multirow{3}{*}{ MSA Intercepts } & \multicolumn{2}{|c|}{ Entire MSA } & \multicolumn{2}{|c|}{ Suburbs only } \\
\hline & Coefficient & $t$-statistic & Coefficient & $t$-statistic \\
\hline & & & & \\
\hline Atlanta & 44.382 & 0.97 & 61.835 & 0.94 \\
\hline Austin & -19.651 & -0.52 & 98.129 & 1.72 \\
\hline Baltimore & -98.453 & -2.64 & 85.065 & 1.49 \\
\hline Boston & -100.065 & -2.74 & 30.629 & 0.54 \\
\hline Charlotte & -44.437 & -1.02 & 99.974 & 1.50 \\
\hline Chicago & -112.261 & -3.11 & 37.245 & 0.66 \\
\hline Cleveland & -105.439 & -2.86 & 50.087 & 0.88 \\
\hline Columbus & -66.315 & -1.68 & 64.600 & 1.12 \\
\hline Dallas & -17.892 & -0.45 & 3.895 & 0.07 \\
\hline Denver & -155.196 & -3.48 & 103.216 & 1.58 \\
\hline Detroit & -99.620 & -2.75 & 53.082 & 0.94 \\
\hline Houston & -6.137 & -0.15 & 49.516 & 0.83 \\
\hline Indianapolis & -108.737 & -2.17 & -4.103 & -0.07 \\
\hline Jacksonville & -39.794 & -0.61 & 35.431 & 0.49 \\
\hline Los Angeles & -84.416 & -2.33 & 27.759 & 0.49 \\
\hline Memphis & 16.283 & 0.37 & 73.474 & 1.14 \\
\hline Miami & -42.339 & -0.87 & 27.438 & 0.44 \\
\hline Milwaukee & -117.334 & -3.09 & 61.108 & 1.06 \\
\hline Minneapolis & -73.403 & -1.97 & 82.146 & 1.45 \\
\hline Nashville & -54.884 & -1.38 & 41.181 & 0.71 \\
\hline New York & -110.045 & -3.07 & 44.129 & 0.79 \\
\hline Philadelphia & -101.881 & -2.81 & 54.356 & 0.97 \\
\hline Pittsburgh & -105.609 & -2.88 & 24.698 & 0.44 \\
\hline Portland & -90.567 & -1.87 & 77.406 & 1.24 \\
\hline St Louis & -88.460 & -2.39 & 57.235 & 1.01 \\
\hline San Diego & 92.728 & 2.59 & -29.833 & -0.53 \\
\hline San Francisco & -107.021 & -2.77 & 69.381 & 1.21 \\
\hline Adjusted $R^{2}$ & 0.052 & & 0.103 & \\
\hline$N$ & 2872 & & 2841 & \\
\hline
\end{tabular}

the indices of concentration for household income tend to increase more among suburbs of the newer MSAs in the south and west, as indicated by the MSAs listed on the left-hand side of Fig. 6.

\section{Conclusion}

Large, older central cities in the northeastern and midwestern regions of the United States have experienced increasing poverty, relative to their own history and relative to the current rates of their surrounding suburbs. Large central cities in the south and west also have higher rates of poverty than their suburbs, but the differences are not as large as those for cities in the northeast and midwest. 
Table 5. Summary of 1970-1990 patterns of concentration of income and poverty in 27 large MSAs

\begin{tabular}{|c|c|}
\hline Suburban concentration patterns & $\begin{array}{c}\text { Central city more } \\
\text { concentrated? }\end{array}$ \\
\hline \multicolumn{2}{|l|}{ Suburban concentration increasing by all measures } \\
\hline Boston & Unclear \\
\hline \multicolumn{2}{|c|}{ Suburban poverty concentration increasing and income } \\
\hline \multicolumn{2}{|c|}{ concentration decreasing } \\
\hline Chicago & Unclear \\
\hline Cleveland & Yes \\
\hline Detroit & Yes \\
\hline New York & Yes \\
\hline St Louis & Yes \\
\hline \multicolumn{2}{|c|}{ Suburban poverty concentration increasing and income } \\
\hline \multicolumn{2}{|c|}{ concentration increasing on one measure } \\
\hline Philadelphia & Yes \\
\hline Pittsburgh & Yes \\
\hline \multicolumn{2}{|c|}{ Suburban poverty concentration increasing on one measure } \\
\hline \multicolumn{2}{|c|}{ and income concentration decreasing } \\
\hline Baltimore & Yes \\
\hline Milwaukee & Yes \\
\hline \multicolumn{2}{|c|}{ Suburban income concentration increasing and poverty } \\
\hline \multicolumn{2}{|c|}{ concentration decreasing } \\
\hline Houston & No \\
\hline Miami & No \\
\hline San Francisco & Unclear \\
\hline \multicolumn{2}{|c|}{ Suburban income concentration increasing and poverty } \\
\hline \multicolumn{2}{|c|}{ concentration decreasing on one measure } \\
\hline Austin & No \\
\hline Dallas & Unclear \\
\hline Denver & Yes \\
\hline Indianapolis & No \\
\hline Jacksonville & No \\
\hline Los Angeles & Unclear \\
\hline Nashville & No \\
\hline \multicolumn{2}{|l|}{ Suburban concentration decreasing by all measures } \\
\hline Minneapolis & Yes \\
\hline \multicolumn{2}{|c|}{ Suburban poverty concentration decreasing and income } \\
\hline \multicolumn{2}{|c|}{ concentration decreasing on one measure } \\
\hline Portland & Yes \\
\hline San Diego & Unclear \\
\hline \multirow{2}{*}{\multicolumn{2}{|c|}{$\begin{array}{l}\text { Suburban poverty and income concentration increasing with } \\
\text { coefficient of variation and decreasing with regression index }\end{array}$}} \\
\hline & \\
\hline Atlanta & Unclear \\
\hline Charlotte & Unclear \\
\hline Columbus & Unclear \\
\hline Memphis & No \\
\hline
\end{tabular}


In this article I have examined whether the changes that have increased poverty in the central cities are also increasing poverty and income concentration among the suburbs in 27 large metropolitan areas. The overall coefficients of variation for median household income and poverty among suburban civil divisions provide evidence that poverty became slightly more concentrated among the suburbs in the last 20 years. But there is no evidence that household income became more concentrated.

Table 5 provides a summary of the findings with respect to changes in the suburban concentrations of income and poverty for each of the 27 MSAs studied. Among the suburbs of the northeastern and midwestern MSAs poverty became more concentrated among the suburban municipalities: Boston, Chicago, Cleveland, Detroit, New York City, St. Louis, Philadelphia, and Pittsburgh. With the possible exception of Chicago and Boston, the central cities of these MSAs experienced greater increases in poverty than did their poor suburbs. ${ }^{16}$ Because these include older American cities where there has been the most differentiation between cities and suburbs in population growth and income levels, these results may provide a harbinger for future growth in spatial inequality in the newer metropolitan areas of the south and west.

Table 5 also shows that the suburbs of southern and western MSAs, while less likely to experience increasing concentrations of poverty, were more likely to experience increases in the concentration of household income. In the southern and western MSAs, however, the central cities were less "troubled", in that they were less likely to have experienced greater concentrations of poverty and income than their suburbs.

\section{References}

Abbot A (2002) Los Angeles and the Chicago School: A comment on Michael Dear. City and Community 1: $33-38$

Bollens SA (1988) Municipal decline and inequality in American suburban rings, 19601980. Regional Studies 22: 277-285

Bourne LS (1993) Close together and worlds apart: An analysis of changes in the ecology of income in Canadian cities. Urban Studies 30: 1293-1317

Fisher RC, Wassmer RW (1998) Economic influences on the structure of local government in US metropolitan areas. Journal of Urban Economics 43: 444-471

Logan JR, Golden RM (1986) Suburbs and datellites: Two decades of change. American Sociological Review 51: 430-437

Pack J (1998) Poverty and urban public expenditures. Urban Studies 35: 1995-2019

Orfield M (2002) American metropolitics: The new suburban reality. Brookings Institution Press, Washington, DC

Orfield M (1997) Metropolitics: A regional agenda for community and stability. Brookings Institution Press, Washington, DC

16 When Figs. 5 and 6 both show that the MSA concentration index exceeds the suburbs only index, then the central city is becoming more concentrated than the suburbs and "yes" is entered in the last column of Table 5. When Figs. 5 and 6 both show that the MSA concentration index is less than the suburbs only index, then the central city is becoming less concentrated than the suburbs and "no" is entered in the last column of Table 5. When one of the figures shows that the MSA concentration index exceeds the suburbs only index, while the other figure shows the opposite, "unclear" is entered in the last column of Table 5 . 
Persky J (1990) Suburban income inequality: Three theories and a few facts. Regional Science and Urban Economics 20: 125-137

Schneider M, Logan JR (1985) Suburban municipalities: The changing system of intergovernmental relations in the mid-1970s. Urban Affairs Quarterly 21: 87-105 
Copyright $\odot 2003$ EBSCO Publishing 